\title{
IMPACT OF COVID 19 PANDEMIC ON ACUTE GENERAL SURGICAL EMERGENCY MANAGEMENT- A TERTIARY CARE HOSPITAL BASED STUDY
}

KEY WORDS: COVID-19,

Acute surgical emergency

\section{Dr. K. K.} Thakuria

Dr. Mon Mohan

Boro

\section{Dr. M. Naveen}

Kumar
Assisstant Professor, Department of General Surgery, Fakhruddin Ali Ahmed Medical College \& Hospital, Barpeta-781301, Assam, India.

Post Graduate Trainee, Department of General Surgery, Fakhruddin Ali Ahmed Medical College \& Hospital, Barpeta- 781301, Assam, India.

Post Graduate Trainee, Department of General Surgery, Fakhruddin Ali Ahmed Medical College \& Hospital, Barpeta-781301, Assam, India.

BACKGROUND: The COVID-19 pandemic is standing as a never before threat to the healthcare systems and hospital operations worldwide. Transmission of coronavirus (COVID-19) is a considerable risk during the perioperative period of surgery. Treatment algorithms have changed in general surgery clinics, as in other medical disciplines providing emergency services.

OBJECTIVES: This study was aimed to evaluate the changes in approach to management and the perioperative outcome of patients with acute surgical emergency during COVID-19 pandemic.

STUDY DESIGN AND METHODS: We performed a retrospective observational study in patients presented with acute surgical emergency between April 2020 to June 2021.

RESULTS: A total of 298 patients were included, among whom $12(3.4 \%)$ were COVID 19 positive. 274 non-COVID patients and 8 COVID-19 positive patients underwent emergency surgery. While 12 non-COVID (4.1\%) and 4 COVID-19 positive patients $(40 \%)$ underwent conservative management.

None of the hospital staff involved in the surgeries of COVID-19 positive patients developed any symptoms related to COVID-19.

CONCLUSION: This study showed that the patients with surgical emergency both with or without COVID-19 infection were successfully treated, without influencing each other, through appropriate isolation measures, although managed in the same hospital. Importance can also be given towards conservative management particularly for COVID-19 positive patients presenting with surgical emergency selectively with proper monitoring. So it can be concluded that, although the management of surgical patients during the COVID-19 pandemic is a global challenge, adequate preparedness and strategic plan to adjust the surgical services can reduce the exposures to this highly contagious virus.

\section{INTRODUCTION:}

In December 2019, an outbreak in the form of pneumonia of unknown origin has occurred in Wuhan in China's Hubei Province, killing 213 of the 9720 infected people in China and spreading in 19 other countries, infecting 106 people by January 31, 2020. By March 2020, the World Health Organization (WHO) declared it as a global pandemic. ${ }^{1}$

The causative virus has been tentatively named "Severe Acute Respiratory Syndrome Coronavirus 2" (SARS-CoV-2) and finally named "Coronavirus Disease 2019 (COVID-19).

India is one of the worst affected countries and has one of the higher mortality numbers. The first confirmed diagnosis of coronavirus (COVID-19) in India was reported in February 2020 and till now June 2021, the total number of COVID-19 cases in India was $30,361,699$ with $3,98,484$ confirmed deaths. ${ }^{2}$

The disease is most commonly seen between the ages of 3079 years and the median age is in the range of $49-59$ years. It has been found very rarely under the age of 15. In about half of people infected with COVID-19, non-serious or overlooked symptoms occur, while in the other half the main symptoms are fever, fatigue and dry cough, myalgia and dyspnea.

During the COVID-19 pandemic, hospital authorities are facing increasingly difficult decisions about how to conserve critical resources (such as hospital and ICU beds, respirators and transfusion capacity) as well as PPE, which is vital for protecting both patients and staff from intra-hospital transmission.

As a consequence, a need for adaptation to surgical services was necessary to conserve the resources as well as to reduce the rate of nosocomial infections to patients and healthcare workers.

All surgeries were postponed with the exception of cancer operations and emergency general surgical procedures. However, conservative management was recommended over operative management unless a patient was in lifethreatening condition. Whether operative or conservative, the decision for each patient should be made very carefully.

Several studies have been done about re-organization of surgical activity under COVID-19 era. However, only a few, have focused on the impact on the management of emergency acute abdomen and trauma surgery. Therefore, we aimed to study on the impact of COVID 19 on management of acute general surgical emergencies and its outcome in this highly controlled environment in a retrospective way.

\section{Objectives:}

This study was aimed to evaluate the changes in approach to management and the perioperative outcome of patients with acute surgical emergency during COVID-19 pandemic.

\section{METHODS}

298 number of patients with surgical emergencies attending Fakhruddin Ali Ahmed Medical College \& Hospital, Barpeta between April 2020 and June 2021 were included in this retrospective study.

In this period each patients were screened at the emergency department for COVID-19 with a nasopharyngeal swab Rapid antigen test and reverse transcription polymerase chain reaction (RT-PCR) swab test.

Those who were chosen for non-operative management were 
kept in a dedicated pre-operative ward separate from nonCOVID ward until RT-PCR test reports were available.

While operating on emergency surgical patients, enhanced personal protection equipment (PPE) including the use of N95 masks was recommended for all theatre personnel, irrespective of the COVID-19 status of the patient. Dedicated pathways for emergency theatres were developed including separate areas for donning and doffing of PPE.

The following variables were analyzed: the demographic profile, indications for surgery, comorbidities, surgical procedure, duration of surgery, length of hospital stay, ventilation support, postoperative complications and mortality. The perioperative COVID-19 status of doctors, and the healthcare workers involved in emergency surgery were also recorded.

Surgical postoperative complications were graded according to the Clavien-Dindo classification. ${ }^{5}$

At the time of discharge, the patients with COVID 19 positive undergone emergency surgery were advised for 7-days home isolation. Postoperative check-up were done on 14th day after discharge with a minimum of personnel, wearing N95 masks and a surgical gloves.

\section{RESULTS}

This study included a total of 298 patients admitted during the period April 2020, to June 2021 with acute surgical emergency, of whom 286 non-COVID (96.6\%) and 12 patients (3.4\%) were Covid-19 positive. Among non-COVID patients 191 was male $(69.7 \%)$ and 83 female $(30.3 \%)$ underwent emergency surgery with a mean age of $32.4+58.1$ years. Among COVID-19 positive patients, 8 patients (60\%) underwent emergency surgery out of which 3 were male $(50 \%)$ and 5 female $(50 \%)$ with a mean age of $34.2 \pm 19.6$ years. $A$ total of 12 non-COVID patients (4.1\%) underwent conservative management, 7 male and 5 female with mean

age $32.3+7.9$ years. While 4 COVID-19 positive patients $(40 \%)$ kept under conservative managemnt witeh mean age $28 \pm 18.2$ years, all were male.

Among non- COVID patients who underwent emergency surgery (276 nos), 11 (3.6\%) patients had more than 1 comorbidities, while among COVID-19 positive only $1(10 \%)$ patient presented with comorbidities.

A mean operative time duration of $77.3+56.9$ minutes was observed in non- COVID patients, while among COVID-19 positive patients mean operative time duration was $120 \pm 53.3$ minutes.

10 non-COVID patients were shifted to ICU post- operatively among which 5 patients needed mechanical ventilation. Mortality rate was $1.8 \%$ among non-COVID patients who underwent emergency surgery. No post-operative complications or mortality was seen among COVID-19 positive patients who underwent emergency surgery. Postoperative hospital stay was seen higher in COVID-19 positive patients with mean duration of $15+3.6$ days than non- COVID patients with mean duration of $7.05+4.3$ days.

Mean duration of hospital stay was $4.8+0.9$ in non-COVID patients under conservative management whereas it is 7.5+0.6 in case of COVID-19 positive patients. No comorbidities was observed in both the groups. However $30 \%$ treatment failure was seen in non-COVID group in patients presented with acute appendicitis.

None of the hospital staff including doctors, nurses, ward boy, OT technician, anesthesiologist involved in surgery of COVID positive patients developed any symptoms related to COVID19 post-operatively.

Table 1: Diagnosis And Total Number Of Cases.

\begin{tabular}{|ll|l|}
\hline Diagnosis & Total \\
\hline 1. & Acute appendicitis & 123 \\
\hline 2. & Appendicular perforation & 52 \\
\hline 3. & Hollow viscus perforation & 46 \\
\hline 4. & Obstructed hernia & 24 \\
\hline 5. & Intestinal obstruction & 18 \\
\hline 6. & Colo- rectal injury following blunt trauma & 12 \\
\hline 7. & Splenectomy & 6 \\
\hline 8. & Carcinoma & 4 \\
\hline 9. & Biliary peritonitis & 3 \\
\hline 10. & Psoas abscess & 2 \\
\hline 11. & Fourniere's gangrene & 2 \\
\hline 12. & Feeding jejunostomy & 1 \\
\hline 13. & Gluteal abscess & 1 \\
\hline 14. & Rectal prolapse & 1 \\
\hline 15. & Burst abdomen & 1 \\
\hline 16. & Faecal fistula & 1 \\
\hline 17. & Liver abscess & 1 \\
\hline & & 298 \\
\hline
\end{tabular}

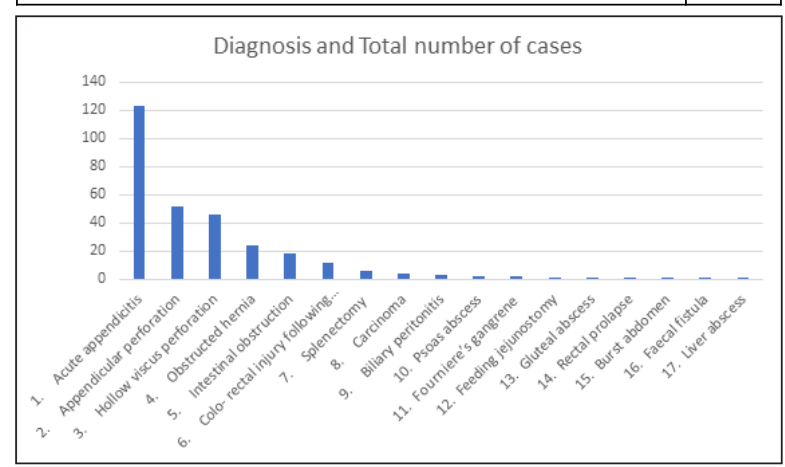

Graph 1: Diagnosis And Total Number Of Cases

Table 2: Profile Of Non-covid Patients Underwent Emergency Surgery

\begin{tabular}{|c|c|}
\hline Parameters & \\
\hline Total patients & $274(95.8 \%)$ \\
\hline Age (years) & $32.4 \pm 58.1$ \\
\hline Male & $191(69.7 \%)$ \\
\hline Female & $83(30.3 \%)$ \\
\hline $\begin{array}{l}\text { No of comorbidities } \\
0 \\
1 \\
2 \\
>3\end{array}$ & $\begin{array}{l}37 \\
11 \\
9\end{array}$ \\
\hline $\begin{array}{l}\text { Comorbidities } \\
\text { Hypertension } \\
\text { Diabetes } \\
\text { Obesity } \\
\text { Smoking } \\
\text { Cancer } \\
\text { Arrhythmia } \\
\text { COPD }\end{array}$ & $\begin{array}{l}22 \\
8 \\
2 \\
51 \\
5 \\
\mathrm{Nil} \\
4\end{array}$ \\
\hline \begin{tabular}{|l} 
Hospitalization on surgical \\
indication \\
ICU \\
Ward \\
\end{tabular} & $\begin{array}{l}10 \\
264\end{array}$ \\
\hline $\begin{array}{l}\text { Mechanical ventilation after } \\
\text { surgery }\end{array}$ & 5 \\
\hline $\begin{array}{l}\text { Days on mechanical } \\
\text { ventilation }\end{array}$ & $\begin{array}{|ll|}2.2 & 1.3 \\
\end{array}$ \\
\hline $\begin{array}{l}\text { Clavien dindo score } \\
\text { Grade I } \\
\text { Grade II }\end{array}$ & $\begin{array}{l}\mathrm{Nil} \\
23\end{array}$ \\
\hline
\end{tabular}




\begin{tabular}{|l|l|}
\hline Grade III & 5 \\
Grade IV & Nil \\
Grade V & 5 \\
\hline Hospital stay (days) & $7.05 \quad 4.3$ \\
\hline OT duration (min) & $77.3 \quad 56.9$ \\
\hline
\end{tabular}

Table 3: Profile Of Covid-19 Patients Underwent Emergency Surgery

\begin{tabular}{|c|c|}
\hline \begin{tabular}{|l|} 
Parameters \\
\end{tabular} & \\
\hline Total patients & $8(60 \%)$ \\
\hline Mean Age (years) & $34.2 \pm 19.6$ \\
\hline Male & 3 \\
\hline Female & 5 \\
\hline \begin{tabular}{|c|} 
No of comorbidities \\
0 \\
1 \\
2 \\
$>3$ \\
\end{tabular} & 7 \\
\hline \begin{tabular}{|l|} 
Comorbidities \\
Hypertension \\
Diabetes \\
Obesity \\
Smoking \\
Cancer \\
Arrhythmia \\
COPD \\
\end{tabular} & $\begin{array}{l}1 \\
1 \\
1\end{array}$ \\
\hline \begin{tabular}{|l} 
Hospitalization at the surgical \\
indication \\
ICU \\
Ward \\
\end{tabular} & 7 \\
\hline $\begin{array}{l}\text { Mechanical ventilation at the } \\
\text { surgical indication }\end{array}$ & NIL \\
\hline \begin{tabular}{|l|} 
Days of mechanical \\
ventilation
\end{tabular} & NIL \\
\hline \begin{tabular}{|l|} 
Clavien dindo score \\
Grade I \\
Grade II \\
Grade III \\
Grade IV \\
Grade V \\
\end{tabular} & 1 \\
\hline Hospital stay (days) & 153.6 \\
\hline OT duration (min) & 12053.3 \\
\hline
\end{tabular}

Table 4: Profile Of Non-covid Patients Who Underwent Conservative Management

\begin{tabular}{|l|l|}
\hline Parameters & \\
\hline Total patients & 12 \\
\hline Age (Years) & $32.3 \pm 7.9$ \\
\hline Male & 7 \\
\hline Female & 5 \\
\hline Comorbidities & NIL \\
\hline $\begin{array}{l}\text { Hospitalization at the surgical indication } \\
\text { ICU } \\
\text { Ward }\end{array}$ & 12 \\
\hline $\begin{array}{l}\text { Mechanical ventilation at the surgical } \\
\text { indication }\end{array}$ & NIL \\
\hline Days of mechanical ventilation & NIL \\
\hline Hospital stay (days) & $4.8 \pm 0.9$ \\
\hline Treatment failure & $30 \%$ \\
\hline
\end{tabular}

Table 5: Profile Of Covid-19 Positive Patients Undergone Conservative Management

\begin{tabular}{|l|l|}
\hline Parameters & \\
\hline Total patients & 4 \\
\hline Age (years) & $28 \pm 18.2$ \\
\hline Male & 4 \\
\hline Female & 0 \\
\hline Comorbidities & NIL \\
\hline $\begin{array}{l}\text { Hospitalization at the surgical indication } \\
\text { ICU }\end{array}$ & 4 \\
\hline
\end{tabular}

|www.worldwidejournals.com $\mid$

\begin{tabular}{|l|l|}
\hline \multicolumn{1}{|c|}{ Ward } & \\
\hline $\begin{array}{l}\text { Mechanical ventilation at the surgical } \\
\text { indication }\end{array}$ & NIL \\
\hline Days of mechanical ventilation & NIL \\
\hline Hospital stay & 7.50 .6 \\
\hline Treatment failure & Nil \\
\hline
\end{tabular}

\section{DISCUSSION}

The COVID-19 pandemic has spread worldwide. From the beginning, governments and healthcare officials in every country started implementing measures to reorganize their services swiftly to fight this crisis and to prevent sharp rise of new COVID-19 cases.

In our hospital also, all surgeries were cancelled or postponed apart from emergency and oncological cases. Due to the increased load during the pandemic, each hospital created dedicated COVID teams that included specialist from different departments, including the general surgery department. Redeployment of the surgeons to such other facilities should not harm the ability to provide timely care for emergency surgical patients since a proportion of patients with acute emergencies will require surgical care and some of those will need an urgent operation.

Hospitals and the healthcare system should have anticipatory plans for acute surgical services. Guidelines should be updated regularly by the specific surgical teams.

In the present study, the changes in approaches and perioperative outcome of general surgical emergency practices resulting from the COVID-19 pandemic were examined in both COVID positive and non- COVID patients.

Our results indicate that, necessary surgeries can still be performed in COVID-19 pandemic if the measures and precautions required are taken.

Importance was also given towards conservative management particularly for COVID-19 positive patients presenting with surgical emergency. Although, the surgeons must be careful while taking such decision and the patients must be regularly monitored for any deterioration.

After careful clinical examination of a patient presenting with acute abdominal emergency and considering imaging results, the first question should be whether postponement of the surgical treatment is possible (ie until the patient is no longer considered potentially infectious or at risk of perioperative complications). If an emergency surgical procedure is necessary (life threatening complication, high risk patient, hemodynamic compromise or shock), the emergency surgeon should check the availability of a dedicated operating theatre with functional and suitable human and technical resources. The golden rule is to involve the smallest number of healthcare staff, correctly protected. For patients planned for non-operative management early clinical diagnosis, adequate source control to stop ongoing contamination, appropriate antimicrobial therapy and prompt resuscitation in critically ill patients are the cornerstone of management of intra-abdominal infection., ${ }^{6,7,8}$

In our study $40 \%$ of the COVID-19 positive patients treated with conservative management with regular follow up and successfully discharged after negative RT-PCR test for COVID-19 and improvement of symptoms. Surgical intervention was planned after 6 wks.

Careful non-operative management with surveillance in noncomplicated acute appendicitis in a pandemic situation is still advocated so that it will not put burden on existing overloaded health system. 
In a survey based study in Ireland, a maximum of surgeons $(74 \%)$ have modified their practice to a predominant conservative approach, but $83 \%$ wanted to revert back to operative management after COVID-19 crisis. ${ }^{11}$

However, surgeons in the UK believe that conservative management should not be undertaken in patients who would normally undergo appendicectomy. They advocate early open appendicectomy in patients with clinical appendicitis even during the pandemic. ${ }^{12}$

In our study although the COVID-19 positive group has exhibited the better outcome in terms of post- operative complications, and recovery and ICU stay, this may be attributed to relative absence of co-morbidities.

Our study had few limitations, one of which is its retrospective nature. Secondly, the diversity of abdominal surgeries performed may have impacted the outcome, as different diseases and procedures are not always comparable. Thirdly the number of COVID-19 positive patients underwent emergency surgery were too low. Also, as it is a recent and still ongoing situation, a relatively short period was analysed which may not be representative.

Therefore, we suggest studies to be done in high scales to evaluate the statistical correlations of different parameters between non-COVID and COVID-19 positive groups.

\section{CONCLUSIONS}

The results of this study showed that the patients with emergency surgery both with or without COVID-19 infection were successfully treated, without influencing each other, through appropriate isolation measures, although managed in the same hospital. So it can be concluded that, although the management of surgical patients during the COVID-19 pandemic is a global challenge, adequate preparedness and strategic plan to adjust the surgical services can reduce the exposures to this highly contagious virus.

We also recommend careful evaluation of every surgical indication on a case-by-case basis. Patients must be evaluated whether it is possible to postpone surgical treatment until the patient is no longer considered potentially infectious or at risk of perioperative complications. If an emergency surgical procedure is necessary the emergency surgeon must supervise the implementation of safety measures in the operating theatre. Trained staff, adequate instruments and strict application of the recommendations are crucial to avoid increasing the risk of contamination.

\section{REFERENCES}

1. World Health Organization . Coronavirus disease (COVID-19). World Health Organization. 2021. Accessed January 15,2021.

https://www.who.int/emergencies/diseases/novel-coronavirus-2019 Google Scholar

2. Worldometer. Coronavirus update (Live): cases and deaths from COVID-19 Virus Pandemic. Worldometers. 2021. p. 1. Accessed January 15, 2021 https://www.worldometers.info/coronavirus Google Scholar

3. Wu Z, McGoogan JM. Characteristics of and Important Lessons From the Corona virus Disease 2019 (COVID-19) Outbreak in China: Summary of a Report of 72314 Cases From the Chinese Center for Disease Control and Prevention.JAMA 2020.

4. Lu R, Zhao X, Li J, Niu P, Yang B, Wu H, et al. Genomic characterisation and epidemiology of 2019 novel coronavirus: implications for virus origins and receptor binding. Lancet 2020;395:565-574

5. Dindo D, Demartines N, Clavien PA (2004) Classification of surgical complications: a new proposal with evaluation in a cohort of 6336 patients and results of a survey. Ann Surg 240(2):205-213

6. Sartelli M, Chichom-Mefire A, Labricciosa FM et al. The management of intraabdominal infections from a global perspective: 2017 WSES guidelines for management of intra-abdominal infections. World JEmerg Surg 2017; 12:29.

7. Emergency surgery during the COVID-19 pandemic: what you need to know for practice. B De Simonel, E Chouillardl, S Di Saverio2, L Pagani3, M Sartelli4, WL Biff15, F Coccolini6, A Pieri3, M Khan7, G Borzellino8, FC Campanile9,LAnsalonil0,F Catenal 1

8. De Simone, Chouillard, Di Saverio, L Pagani, M Sartelli, WL Biffl, F Coccolini et al.Emergency surgery during the covid-19 pandemic: what you need to know for practice. Ann R Coll Surg Engl 2020;000: 1-10 l

9. Surender Vermal \& Pradeep Gargl \& Anjali Verma2 \& Vivek Sirohil; Careful Non-operative Management with Surveillance of Acute Appendicitis During
COVID-19 Pandemic; Indian Journal of Surgery (February 2021) 83(1):388-389

10. Lotfallah A, Aamery A, Moussa G, et al. (March 24, 2021) Surgical Versus Conservative Management of Acute Appendicitis During the COVID-19 Pandemic: A Single-Centre Retrospective Study. Cureus 13(3): el4095. DOI 10.7759/cureus.14095

11. Kelly ME, Murphy E, Bolger JC, Cahill RA (2020) COVID-19 and the treatment of acute appendicitis in Ireland: a new era or short-term pivot? Color Dis 22:648-649.

12. Scott C, Lambert A (2020) Managing appendicitis during the COVID-19 pandemic in the UK. BrJ Surg 107:e271. 